
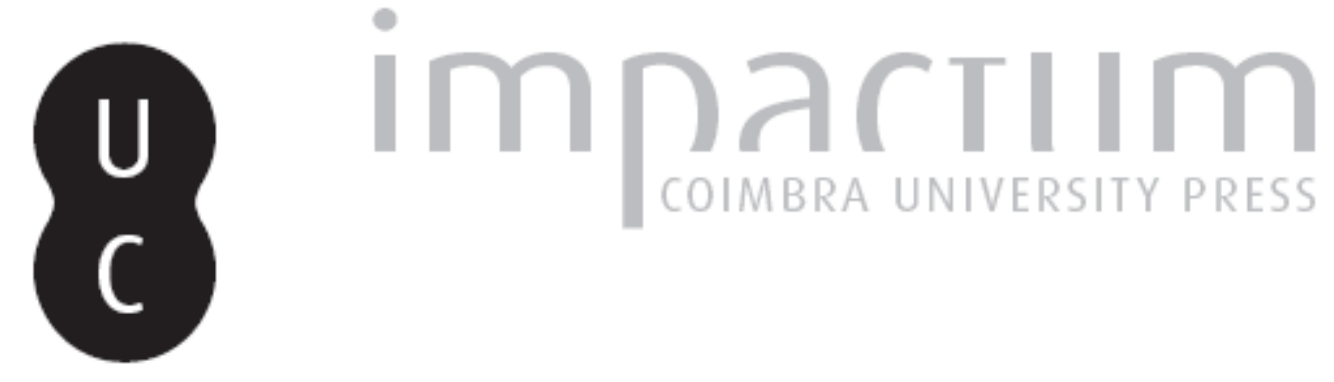

Três acidentes e uma avaliação pericial em Direito Civil: um desafio médico-legal

Autor(es): $\quad$ Oliveira, C; Corte-Real, F; Vieira, DN

Publicado por: Imprensa da Universidade de Coimbra

URL persistente:

URI:http://hdl.handle.net/10316.2/42160

DOI:

DOI:http://dx.doi.org/10.14195/1647-8630_26_4

Accessed : $\quad$ 26-Apr-2023 13:05:23

A navegação consulta e descarregamento dos títulos inseridos nas Bibliotecas Digitais UC Digitalis, UC Pombalina e UC Impactum, pressupõem a aceitação plena e sem reservas dos Termos e Condições de Uso destas Bibliotecas Digitais, disponíveis em https://digitalis.uc.pt/pt-pt/termos.

Conforme exposto nos referidos Termos e Condições de Uso, o descarregamento de títulos de acesso restrito requer uma licença válida de autorização devendo o utilizador aceder ao(s) documento(s) a partir de um endereço de IP da instituição detentora da supramencionada licença.

Ao utilizador é apenas permitido o descarregamento para uso pessoal, pelo que o emprego do(s) título(s) descarregado(s) para outro fim, designadamente comercial, carece de autorização do respetivo autor ou editor da obra.

Na medida em que todas as obras da UC Digitalis se encontram protegidas pelo Código do Direito de Autor e Direitos Conexos e demais legislação aplicável, toda a cópia, parcial ou total, deste documento, nos casos em que é legalmente admitida, deverá conter ou fazer-se acompanhar por este aviso.

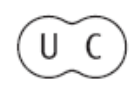




\title{
Três acidentes e uma avaliação pericial em Direito Civil Um desafio médico-legal
}

\author{
Oliveira $\mathrm{C}^{1}$, Corte-Real $\mathrm{F}^{1,2}$, Vieira $\mathrm{DN}^{2}$
}

Resumo: Três acidentes e uma avaliação pericial em Direito Civil. Um desafio médico-legal. Entre os vários factores que, directa ou indirectamente, poderão ter influência na valoração das consequências resultantes da actuação de um determinado evento traumático encontra-se o estado patológico anterior do sinistrado, um problema sempre complexo no contexto da reparação.

Apresenta-se um caso estudado no âmbito da avaliação do dano corporal em Direito Civil, no qual as lesões traumáticas no membro inferior direito provocaram um agravamento do estado patológico anterior do indivíduo. Para valoração do défice funcional permanente, os autores optaram por se desviar do intervalo de desvalorização previsto na tabela de incapacidades, uma vez que as tabelas, de um modo geral, não impõem rigidez tabelar e permitem variações fundamentadas. As tabelas de incapacidades não excluem, na sua essência, a personalização, dado que no relatório pericial deve constar a real repercussão das sequelas no quotidiano do sinistrado. Pretendeu-se assim realçar a importância de uma descrição pormenorizada no que se refere à efectiva repercussão que as sequelas decorrentes de um traumatismo provocam nas actividades da vida diária de um determinado indivíduo.

Palavras-chave: Estado anterior; avaliação do dano corporal; Direito Civil.

Summary: Three accidents and a case of bodily injury evaluation in Civil Law. A forensic challenge.

The prior state of the affected individual is among the various factors which may have a direct or indirect influence in the evaluation of the consequences resulting from the action of a traumatic event.

Instituto Nacional de Medicina Legal e Ciências Forenses, I.P.

Faculdade de Medicina da Universidade de Coimbra 
We report a bodily injury case in Civil Law evaluation, where traumatic injuries in the right lower limb had caused a worsening of the prior pathological state of the individual. For valorization of permanent functional deficit, the authors have chosen to deviate from the predicted impairment range in the table of disabilities, since the tables, in general, do not require rigid and allows reasoned variations. Disability tables, in essence, do not exclude the personalized damage, however the expert report must contain the real impact of sequelae in daily life of the victim. Thus, the aim was to highlight the importance of a detailed description regarding the actual repercussion that the consequences arising from trauma cause in the activities of daily life of a particular individual.

Key-words: Prior state; bodily injury evaluation; Civil Law.

\section{INTRODUÇÃ̃}

Na actividade médico-legal, mais concretamente no âmbito da avaliação do dano corporal pós-traumático, somos frequentemente confrontados com situações de assinalável complexidade, nomeadamente no que se refere ao estabelecimento da imputabilidade médica, sobretudo quando a pessoa é já portadora de um estado anterior, decorrente de doenças e/ou acidentes sucessivos. A complexidade nestas situações reside na dificuldade que os peritos médicos podem encontrar na interpretação das sequelas alegadas e constatadas bem como, em reconhecer que existe a variável estado anterior em jogo, o que desde logo pode por si só ser complexo. Além disso, encontrando-se na posse de todos os dados relevantes, o médico deve conseguir pronunciar-se sobre a influência de um estado patológico preexistente na situação clínica actual do examinando.

Frequentemente confrontados com a existência de uma patologia ou lesão anterior que pode ter influenciado ou sofrido influência pelas consequências do traumatismo o perito deve por isso assegurar que qualquer perícia médico-legal contempla um exame detalhado, preciso e esclarecedor, de modo a que, por comparação com a perícia relativa ao evento traumático em apreço, se possa reconhecer, do ponto de vista médico-legal, a influência exercida pelo estado patológico anterior. Dever-se-á tentar esclarecer o estado do indivíduo no momento do traumatismo e o seu estado actual decorrente das consequências do evento traumático. Este facto faz com que a existência de um estado anterior represente, ainda hoje, um desafio na prática médico-legal.

Verifica-se que a forma como é valorado o estado anterior em Direito Civil, sem critérios de homogeneidade entre os diversos peritos médicos, origina, com alguma frequência, dificuldades interpretativas que impedem 
uma correcta avaliação do dano corporal pós-traumático. Mesmo na vertente clínica da abordagem médico-legal desta temática, as orientações específicas sobre a sua metodologia de avaliação são escassas.Com efeito, encontramos alguma diversidade de critérios, senão mesmo uma relevante disparidade de valores de desvalorização arbitrados. Estas discrepâncias nem sempre são fáceis de compreender, havendo ainda um caminho doutrinal a percorrer no sentido de racionalizar e objectivar a valoração do dano corporal. Assim, e porque é premente encontrar um sistema justo de reparação, constitui matéria de primordial importância a definição de critérios de harmonização quando um estado anterior está presente, de modo a que todas as vítimas sejam avaliadas de forma equitativa e proporcional. Esta uniformização de critérios tem como objectivo principal evitar ressarcimentos aleatórios, podendo servir de auxílio a um juiz quando na fundamentação de casos análogos.

Neste domínio, importa referir que as concausas preexistentes são as mais frequentes e as que geralmente acarretam maiores dificuldades no estabelecimento do nexo de causalidade e na delimitação das consequências lesivas de um determinado evento traumático. Em situações de verdadeira concausalidade, em que há influência da concausa sobre as consequências do traumatismo, não se deve afastar da avaliação do nexo de causalidade o eventual agravamento do estado patológico anterior. Note-se que o estudo da concausalidade é ponto fundamental para a avaliação pericial, não atingindo um objectivo apenas académico, mas, também, jurídico e social, uma vez que o problema da sinistralidade se estende à sociedade no seu contexto geral.

A pouca informação sobre esta matéria a nível nacional, sobretudo na vertente médico-legal, aliada à complexidade da sua análise e à falta de uniformização neste tipo de avaliação, constituíram as principais motivações deste trabalho. A este propósito e de modo a enfatizar a metodologia de avaliação médico-legal, bem como a forma de valorização do estado anterior, aborda-se um caso de avaliação do dano corporal em Direito Civil, onde as lesões traumáticas provocaram um agravamento do estado patológico preexistente. Contudo, para que esta análise médico-legal fique melhor exemplificada debruçar-nos-emos previamente sobre alguns aspectos particulares da avaliação do dano corporal de natureza cível, quando estamos perante um estado patológico anterior.

Cabe referir que o art. ${ }^{\circ} 563$ do Código Civil Português define que «a obrigação de indemnização só existe em relação aos danos que o lesado provavelmente não teria sofrido se não fosse a lesão». Daqui se entende que não há que ressarcir todos e quaisquer danos que sobrevenham ao 
evento, mas tão só os que ele tenha na realidade provocado. O autor do traumatismo não tem responsabilidade sobre o estado anterior e, por isso, não seria correcto ter que indemnizar num montante superior ao necessário em outro indivíduo sem esse estado patológico anterior. Mas também menos correcto seria se o ofendido, que vivia e viveria sempre sem um determinado dano, ficasse afectado numa determinada função ou estrutura e ficasse sem direito a um ressarcimento indemnizatório. Os problemas médico-legais são, sem dúvida, complexos, mas convirá sublinhar que a melhor apreciação desta problemática será a que envolve a averiguação de quais as reais consequências resultantes do complexo estado anterior-evento traumático. Este mesmo artigo consagra ainda a doutrina da causalidade adequada que não pressupõe a exclusividade do factor etiológico condicionante do dano. A regra geral é o princípio da reparação integral do dano que procura restaurar o status quo ante da vítima, ou seja, colocá-la em situação equivalente à anterior ao facto danoso, concepção que muitas vezes se converte em utopia, restando a possibilidade de compensar, de forma indemnizatória, pelo dano sofrido. É tarefa do perito médico, sempre que possível, proporcionar uma avaliação susceptível de proporcionar uma reparação da vítima da forma mais justa e equitativa, pelo dano sofrido.

Ainda assim, será o próprio perito médico, com base nos seus conhecimentos técnico-científicos, que apreciará a influência do estado anterior sobre a evolução da situação. Contudo, nalguns casos, pela complexidade da sua análise, como mais à frente veremos, podem surgir dificuldades na abordagem pericial.

\section{DESCRIÇÃO DO CASO}

Exame pericial efectuado a examinando com 47 anos de idade, que sofreu um acidente de viação em 2008, do qual resultou uma fractura supracondiliana do fémur direito. À entrada na unidade hospitalar apresentava úlceras varicosas em ambos os membros inferiores. Foi efectuada osteossíntese distal do fémur com placa e parafusos e imobilização com tala gessada posterior. Posteriormente foi orientado para tratamentos de fisioterapia. Radiografia efectuada cerca de sete meses após o evento traumático evidenciou osteoporose grave, consolidação viciosa do fémur e da tíbia direitos, bem como sinais de artrose do joelho. $\mathrm{O}$ caso descrito exigiu porém algumas considerações adicionais quanto ao estabelecimento do nexo de causalidade entre o traumatismo e o quadro sequelar 
apresentado pelo examinado à data da avaliação pericial, uma vez que na documentação clínica disponibilizada, bem como na informação prestada pelo sinistrado, este era, à data do evento em consideração, já portador de um estado patológico resultante de dois traumatismos anteriores no membro inferior direito. Com efeito, em 1995havia sofrido uma fractura do calcâneo direito na sequência de queda, sendo tratado conservadoramente. Em 2002, sofreu fractura cominutiva complexa dos pratos da tíbia direita na sequência de um acidente de viação, tendo sido submetido a tratamento cirúrgico. Na documentação clínica referente às consultas subsequentes a este acidente de 2002 há referência a um quadro sequelar resultante no membro inferior direito, designadamente uma cicatriz viciosa na perna, uma pseudartrose proximal da tíbia com desvio em varo, um encurtamento do membro de $2 \mathrm{~cm}$ comparativamente com o contralateral, uma amiotrofia generalizada não quantificada e uma limitação funcional do joelho igualmente não quantificada. No seguimento destes traumatismos anteriores, o examinando não realizou qualquer avaliação pericial, nem tão pouco foi seguido em serviços médicos de companhias de seguros. Na perícia médico-legal efectuada na sequência do acidente sofrido em 2008, o sinistrado reconhece que já não fazia corrida nem marcha rápida à data do traumatismo em apreço, sentindo, no entanto, um agravamento da sua claudicação, dificuldades acrescidas na marcha em pisos irregulares e no descer e subir escadas, exigindo o apoio de um corrimão e fenómenos dolorosos acrescidos no joelho direito e na coluna lombar. Objectivamente, apresentava uma marcha moderadamente claudicante, com recurso a palmilha compensatória no pé direito, duas cicatrizes lineares, de características cirúrgicas (uma localizada na coxa e outra na perna), um encurtamento aparente do membro inferior direito de cerca de $4 \mathrm{~cm}$ comparativamente com o membro contralateral, uma amiotrofia de $4 \mathrm{~cm}$ e $3 \mathrm{~cm}$ na coxa e na perna, respectivamente, um joelho em varo, uma rigidez da flexão activa do joelho $\left(90^{\circ}\right)$, uma anquilose da tibiotársica e alterações tróficas acentuadas semelhantes às do membro contralateral. $\mathrm{O}$ estudo radiológico dos membros inferiores efectuado à data da avaliação pericial evidenciou uma consolidação do fémur direito sem significativo desalinhamento ósseo, material de osteossíntese com placa e parafusos no fémur, alterações estruturais da epífise na região metafisária proximal da tíbia homolateral, com grande deformação sobretudo do prato tibial lateral, alterações degenerativas do joelho direito, com irregularidade e esclerose das superfícies articulares e encurtamento do membro inferior direito que se quantificou em cerca de $43 \mathrm{~mm}$, sendo este encurtamento em $8 \mathrm{~mm}$ a nível do fémur e $35 \mathrm{~mm}$ na tíbia (fig.1). 


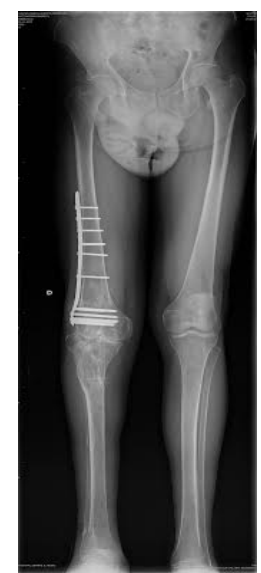

Fig. 1 Rx métrico extralongo dos membros inferiores realizado à data da avaliação pericial

Fonte: Centro Hospitalar do Baixo Vouga, E.P.E

\section{ANÁLISE E PROPOSTA DE AVALIAÇÃO PERICIAL}

Face ao anteriormente exposto, reconhece-se que o traumatismo em apreciação, ocorrido em 2008, tenha agravado o quadro anátomo-funcional do membro inferior direito do examinado. Com efeito, a situação de agravamento que deverá ser imputada ao evento traumático em apreço, traduzir-se-á na diferença entre o estado patológico preexistente e aquele actualmente apresentado pelo sinistrado. Contudo, apenas é possível efectuar-se uma estimativa do valor de défice funcional correspondente à situação de agravamento, uma vez que, para um maior rigor médico-legal, seria necessário uma avaliação pericial referente à situação patológica preexistente de modo a diferenciar do valor de défice funcional actual.

Apesar de já mencionado, importa realçar que o Rx extralongo (métrico) dos membros inferiores evidencia uma consolidação da fractura do fémur direito sem significativo desalinhamento ósseo, enquanto, a um nível mais distal, foram observadas alterações estruturais com grande deformidade dos pratos tibiais à direita, muito possivelmente relacionadas com sequelas do acidente sofrido em 2002, do qual resultou fractura cominutiva complexa a esse nível. Além do exposto, o estudo imagiológico por nós solicitado permitiu quantificar a dismetria dos membros inferiores que o examinado apresentava clinicamente à data da avaliação pericial. Este exame métrico evidenciou uma dismetria estrutural de $43 \mathrm{~mm}$ do membro inferior direito, à custa de apenas 
$8 \mathrm{~mm}$ de encurtamento a nível do fémur e $35 \mathrm{~mm}$ a nível da tíbia, esta última correspondendo à localização atingida no acidente ocorrido em 2002. Apesar da magnitude da dismetria nos membros inferiores com significado clínico permanecer controversa na literatura científica, o encurtamento estrutural de $8 \mathrm{~mm}$ do membro inferior direito admitido como sendo resultante do evento traumático em apreço, não é, regra geral, alvo de reparação, uma vez que de acordo com a Tabela Nacional de Incapacidades em Direito Civil (Anexo II do Decreto-Lei 352/07, de 23/10) a dismetria é apenas valorizável quando de valor superior a $1 \mathrm{~cm}$. Esta orientação tabelar pode de alguma forma ser justificada pelo facto de indivíduos com dismetrias inferiores a $1 \mathrm{~cm}$ exercem geralmente uma compensação funcional através do seu lado de maior comprimento, o suficiente para não acarretar alterações do padrão da marcha e consequente repercussão funcional. Esta adaptação é usualmente obtida com uma báscula da bacia, uma flexão da anca e do joelho no lado de maior comprimento ou até com uma flexão plantar da tibiotársica do lado encurtado. Note-se, porém, que no caso em apreço esta assimetria não é passível de atenuação apenas com uma adaptação funcional, uma vez que o examinado era já portador de um encurtamento radiológico de $35 \mathrm{~mm}$ da tíbia direita à data do traumatismo, ocorrendo deste modo, um agravamento da dismetria, que consequentemente implicará uma alteração da espessura da palmilha compensatória que o examinado possuía no pé direito ou a implantação de uma ortótese plantar, de modo a equilibrar toda a biomecânica do corpo.

Nesta conformidade e com base nos elementos clínicos disponíveis, reconheceu-se existir nexo de causalidade entre o traumatismo e um ligeiro agravamento funcional do membro inferior direito. Assim, poderia propor-se um défice funcional permanente de 3 pontos, de acordo e por analogia com os códigos da Tabela referentes à gonalgia direita por agravamento de patologia prévia (Mf1310) e ao encurtamento de $8 \mathrm{~mm}$ do membro inferior num indivíduo que já apresentava um encurtamento prévio de $35 \mathrm{~mm}$ (publicado como Mc0625). Assumiríamos, porém, uma desvalorização de 2 pontos pela gonalgia e de 1 ponto pelo encurtamento, apesar do mencionado código apresentar como intervalo de desvalorização 2 a 3 pontos para as dismetrias superiores a $1 \mathrm{~cm}$ e inferiores a $3 \mathrm{~cm}$. A alusão a este caso visa igualmente reforçar o que a doutrina médico-legal defende no que se refere ao carácter apenas orientativo das tabelas. Deve ter-se sempre presente que as tabelas não impõem rigidez tabelar e que permitem variações fundamentadas, atendendo sobretudo ao nível da adaptação individual anterior à ocorrência do acidente, garantindo a reprodutibilidade e quantificando o atingimento na integridade físico-psíquica clinicamente constatável. Acresce que, como instrumentos médicos que são, as tabelas deverão ser utilizadas por médicos com suficiente espaço de liberdade 
para lhes permitir uma ponderação adequada à realidade do examinado. . As tabelas de incapacidades não excluem, na sua essência, a personalização, dado que no relatório pericial deve constar a repercussão das sequelas nas actividades diárias do sinistrado. Elas pretendem uniformizar as decisões judiciais no que respeita à reparação pecuniária das sequelas resultantes de um evento traumático, entre outros objectivos. Não obstante o exposto, as tabelas apenas possuem carácter indicativo, reconhecendo-se que o perito médico possa desviar-se dos valores de incapacidade previstos nas mesmas, desde que devidamente fundamentado à luz dos princípios gerais delineados com a criação das referidas tabelas e do exame pericial efectuado (artigo 2, $\mathrm{n}^{\circ} 3$, do Decreto-Lei n⿳352/2007 de 23/10).Tendo em conta os critérios e valores orientadores definidos no Anexo II do Decreto-Lei no352/2007 de 23/10,bem como a especificidade do caso em apreço, reconhece-se ser possível que o agravamento em $8 \mathrm{~mm}$ do encurtamento do membro inferior direito seja alvo de reparação a título de défice funcional permanente, com o valor de 1 ponto. Com efeito, os valores definidos na tabela representaram uma linha orientadora para o coeficiente de desvalorização proposto nesta situação.

Algo que merece ainda a nossa reflexão crítica é a tendência de alguns peritos médicos para se transformarem em meros aplicadores de regras, tabelas e leis. Não nos parece ser boa prática a mera asserção tabelar utilizada na maioria das perícias médico-legais, até porque números tabelados não são sinónimos de uma justa reparação. Enquanto peritos médicos, temos o dever de estar atentos e considerar a pessoa humana no seu todo. Apesar de sermos defensores das tabelas, devemos conceder-nos a liberdade de questionar, rebater e poder divergir do que elas propõem, caso seja necessário. A nosso ver, é esta evidência de razoabilidade que distingue um verdadeiro perito médico-legal. Não está em causa a valoração de tais danos, antes e apenas verificar de que forma devem ser valorados.

Ainda no caso descrito e no que se refere ao Dano Estético Permanente, deverá ser considerada a cicatriz cirúrgica na coxa, além do ligeiro agravamento da claudicação. Quanto à necessidade de ajudas técnicas reconhece-se que possa exigir o uso de uma palmilha compensatória no pé direito mais espessa do que aquela que eventualmente utilizava antes do evento traumático sofrido em 2008.

\section{Referências bibliográficas}

- Anexo II do Decreto-Lei no 352/2007, de 23 de Outubro.

- Código Civil Português. 